\title{
Gestational diabetes mellitus in pregnancy increased erythropoietin level affecting differentiation potency of haematopoietic stem cell of umbilical cord blood
}

Mohd Razif Mohd Idris

Universiti Kebangsaan Malaysia

Fazlina Nordin ( $\square$ nordinf@ppukm.ukm.edu.my )

Universiti Kebangsaan Malaysia https://orcid.org/0000-0002-7053-4580

Zaleha Abdullah Mahdy

Universiti Kebangsaan Malaysia

$S$ Fadilah Abd Wahid

Universiti Kebangsaan Malaysia

Research article

Keywords: Umbilical cord blood (UCB), Haematopoietic stem cell (HSC), Gestational diabetes mellitus (GDM), Colony forming unit (CFU), Erythropoietin (EPO), Enzyme-linked immunosorbent assay (ELISA).

Posted Date: September 24th, 2020

DOI: https://doi.org/10.21203/rs.3.rs-40849/v2

License: (a) (i) This work is licensed under a Creative Commons Attribution 4.0 International License.

Read Full License 


\section{Abstract}

Background The in utero environment has many factors that can support cell differentiation. Cytokines, chemokines, and growth factors play big roles in haematopoietic mechanisms. Some diseases like gestational diabetes mellitus (GDM) might affect the environment and quality of haematopoietic stem cell (HSC). This study aims to investigate the adverse effects of GDM on umbilical cord blood (UCB) HSC regarding its differentiation potency, including the UCB parameters used for banking and transplantation purposes.

Methods UCB-HSC was collected from 42 GDM and 38 normal pregnancies. UCB-HSC was isolated and further enriched using immuno-magnetic separation beads (MACS). The UCB-HSC were cultured in methylcellulose media to investigate the differentiation potency. The level of erythropoietin (EPO) and insulin in the UCB plasma was measured using enzyme-linked immunoassay (ELISA) technique.

Results The UCB parameters, i.e., volume, total nucleated count (TNC), and total CD34+ cells, were significantly reduced in the GDM group compared to the control group. The number of HSC progenitor colonies was significantly reduced in the GDM group, except for progenitor BFU-E, which was significantly increased $(\mathrm{GDM}=94.19 \pm 6.21$, Control $=73.61 \pm 2.73, p=0.010)$. This data was associated with a higher EPO level in the GDM group. However, the insulin level in the GDM group was comparable to the control group.

Conclusion Our results suggest that the changes in the in utero environment due to abnormalities during pregnancy, such as GDM might affect the differentiation potency of UCB-HSC. These findings can be considered as an additional parameter for the inclusion and exclusion criteria for UCB banking, particularly for mothers with GDM.

\section{Background}

Umbilical cord blood (UCB) has been used as an alternative source of haematopoietic stem cells (HSCs) for transplantation. Over 30,000 UCB transplants have been performed worldwide for the treatment of various diseases. Despite its small volume, i.e., approximately $100 \mathrm{~mL}$ per unit, UCB is capable of rapid growth, allowing rapid regeneration of the entire HSC population compared to bone marrow (1). The advantages of UCB include easy acquisition, lack of risk to the donors (mothers), less risk of infection, immediate availability, and less rigid criteria for the human leukocyte antigen (HLA) matching and low incidence of graft versus host disease (2). However, an insufficient number of HSCs in one unit of UCB causes the slowdown in haematopoietic recovery, especially in adult and child patients (3). The successful outcome of transplantation is closely correlated to the nucleated cell count (NCC) and the number of CD34+ cells $(4,5)$.

The ideal number of NCC for transplantation is $1^{\prime} 10^{7}$ to $3^{\prime} 10^{7}$ cells $/ \mathrm{kg}$ of recipient weight, whereby the higher the dose of NCC, the shorter the engraftment period $(1,6)$. Meanwhile, for CD34+ cells, the best dose for transplantation is $>1.7^{\prime} 10^{5}$ cells $/ \mathrm{kg}$. A study showed that only $22 \%$ of patients survived for 
more than one year after receiving NCC $<3.7^{\prime} 10^{7}$ cells $/ \mathrm{kg}$, while $41 \%$ of patients receiving at least $3.7^{\prime}$ $10^{7}$ cells $/ \mathrm{kg}$ had more than one year rate of survival (2). On the contrary, one study reported that patients receiving CD34+ cells of $\left\langle 1.7^{\prime} 10^{5}\right.$ cells/kg and $1^{\prime} 10^{7}$ cells/kg NC had high mortality rates (4). Based on these findings, most UCB banks have set policies for selecting high-quality UCB units for storage purposes (7).

To date, very few studies have been conducted to examine the effects of gestational diabetes mellitus (GDM) on the quality of umbilical cord blood-haematopoietic stem cell UCB-HSC). GDM is defined as glucose intolerance with the onset or first recognition during pregnancy. A previous study of a single centre experience at Hospital Universiti Kebangsaan Malaysia (UKM) reported an overall poor outcome of GDM pregnancy with a high level of HbA1c, but the effect on the quality of UCB-HSC was not further investigated (8). Data from developed countries suggest that the prevalence of GDM is increasing, being almost $10 \%$ of pregnancies and probably reflecting the global obesity epidemic. At our centre, the prevalence can be as high as $24.9 \%$ (9). While considering longer-term outcomes for the baby, the evidence is gradually mounting that GDM adds an intrauterine environmental risk factor (10). GDM may affect placental haemodynamic with abnormal umbilical artery blood flow, which can alter the in utero environment, such as influencing the levels of erythropoietin (EPO) and insulin (11), resulting in foetal hypoxia.

EPO is a hormone that plays a role in regulating foetal erythropoiesis (15). A pathological issue has been detected in the process of erythropoiesis in infants of diabetic mothers, attributable to abnormalities in the metabolic system and intra-uterine hypoxia $(15,16)$.

Meanwhile, the high levels of insulin in the UCB plasma could interfere with foetal growth and subsequently alter the process of angiogenesis and vascularisation that could affect the quality of UCBHSC (11). These two hormones, EPO and insulin, may provide a good microenvironment for cell growth and haematopoiesis (17); thus, producing good quality HSC. High EPO levels are often correlated with diabetic pregnancies and hypoxia, while a high insulin level might impair the match between the supply and demand from the placenta. This study aims to investigate whether GDM might influence the quality and in vitro differentiation of UCB-HSC and its correlation with EPO and insulin levels.

\section{Methods}

\section{Subjects}

This prospective case-control study was conducted on 42 pregnancies with GDM, and 38 healthy pregnancies, which were screened and recruited at 20-24 weeks of gestation and on monthly follow-up and admitted for delivery at Universiti Kebangsaan Malaysia Medical Centre (UKMMC). The study was approved by the Research Ethics Committee of UKMMC. GDM was defined according to the American College of Obstetricians and Gynaecologists guidelines, with abnormal glucose values at fasting and 2 hours post-prandial (75 g OGTT test) (18). Healthy subjects (the control group) consisted of pregnant 
women of similar age, parity, and gestational age without any serious disease, including preeclampsia (PE) and GDM. The control group selection was based on the observational method. All subjects must undergo blood screening for hepatitis B, hepatitis C, cytomegalovirus, syphilis, and human immunodeficiency virus 1-2 as per hospital practice. The subjects were also screened for genetic diseases, such as pregestational diabetes mellitus (DM), chronic hypertension, autoimmune diseases, renal or liver impairment, and haematological disorders as per medical history. Meanwhile, the screening for multiple pregnancies and foetal anomalies or infection was performed using the detailed ultrasound scan. Additional File 1 shows a summary of the experimental design of the present study.

\section{Umbilical cord blood (UCB) collection}

Trained staff nurses performed UCB collections according to the hospital protocol during delivery. It was performed before placental dismissal in all patients to avoid interfering with the delivery of the baby, while still preserving the sterility of the UCB. Briefly, the cord was clamped and cut after delivery of the baby. A four to eight-inch length of the cord was cleaned with alcohol and betadine. A 16-gauge needle from a standard cord blood collection bag set containing $22 \mathrm{~mL}$ of citrate phosphate dextrose (CPD) anticoagulant was inserted into the umbilical vein, and cord blood was allowed to flow freely into a 157 $\mathrm{mL}$ collection bag. The needle was removed when the blood flow stopped. An identical collection method was used for the control group. Blood samples were stored at $4{ }^{\circ} \mathrm{C}$ immediately after collection before being collected by the laboratory personnel. Samples were processed within 24 hours after collection.

\section{Mononuclear cell (MNC) collection and CD34+ cells selection}

The UCB mononuclear cells (MNCs) were extracted through density centrifugation using Lymphoprep solution (Stem Cell Technologies, USA). Briefly, the MNC layer was aspirated into new tubes and suspended with phosphate-buffered saline (PBS; 1:3 ratios) and centrifuged at $1000 \mathrm{rpm}$ for 10 minutes. The pellet was washed twice with PBS and resuspended in $300 \mathrm{~mL}$ of Iscove's Modified Dulbecco's Medium (IMDM). CD34+ cell selection was performed according to the manufacturer's protocol (MACS CD34 MicroBead Kit Human). Briefly, $100 \mathrm{~mL}$ of blocking reagent and $100 \mathrm{~mL}$ of CD34+ microbeads solution was added, followed by 30 minutes incubation at $2-8{ }^{\circ} \mathrm{C}$. The microbeads-conjugated cells were separated using a magnetic column following cell counting by haemocytometers.

\section{Colony Forming Unit (CFU) Assay}

The colony-forming unit (CFU) assay was performed to observe the differentiation potency of the UCBHSC enriched CD34+ cells and to quantify the numbers of each differentiated haematopoietic progenitor cells. The assay was performed using a Methocult ${ }^{\text {tM }}$ Kit (Stemcell Technologies, USA). Briefly, a total of 5 $10^{3}$ of enriched CD34+ cells were seeded in $35 \mathrm{~mm}$ Petri dish with differentiation media, and further incubated at $37^{\circ} \mathrm{C}$ for 14 days. The HSC differentiated colonies, i.e., colony-forming unit granulocyte, erythrocyte, monocyte, megakaryocyte (CFU-GEMM); colony-forming unit granulocyte, monocyte (CFU$\mathrm{GM})$; burst-forming unit erythrocyte (BFU-E); colony-forming unit monocyte (CFU-M); and colony-forming unit granulocyte (CFU-G) were counted under an inverted microscope. The experiments were done in 
duplicate for each sample. Additional File 2 shows the morphology of UCB-HSC progenitor cell differentiation from a control subject as reference.

\section{Insulin Assay}

The plasma insulin level was determined using Quantikine ${ }^{\circledR}$ ELISA Human Insulin (R\&D Systems ${ }^{\mathrm{TM}}$, USA) according to the manufacturer's protocol. Briefly, the plasma taken during MNC density centrifugation, control, and standard samples were added to the coated wells to allow antigen-antibody binding. The plate was incubated at room temperature and washed four times. The biotinylated antibody was added to each well. The excess detection antibody was removed, and an enzyme (Streptavidin-HRP) was added and incubated to complete the four-member sandwich binds (antibody-antigen-detection antibodyenzyme). After the second incubation, the plate was washed four times to remove all unbound enzymes, and the final solution (stabiliser substrate solution) was added to produce the colour of the substrateenzyme-linked product. The intensity of the coloured product (optical density, OD) was compared against the concentration of human insulin, which can be determined using an ELISA plate reader at $450 \mathrm{~nm}$ wavelength. The concentration of human insulin in tested samples was obtained by comparing the OD of the samples to the standard. The overall incubation time was four hours in total, with 30 minutes of hands-on time. Each sample was run in duplicate.

\section{Erythropoietin (EPO) Assay}

The plasma EPO level was determined using pre-coated Human EPO ELISA Kit (Elabscience Biotechnology Inc., USA) according to the manufacturer's protocol. Briefly, standards and samples (plasma) were added to a microplate and combined with the specific antibody. After the first incubation, the plate was washed four times, and the biotinylated antibody was added, followed by Streptavidin-HRP in each well. The plate was further incubated, washed, and the enzyme-substrate reaction was terminated by the addition of the stop solution. The OD, proportionate to the concentration of human EPO, was measured using an ELISA plate reader at $450 \mathrm{~nm}$. The concentration of human EPO in tested samples was obtained by comparing the OD of the samples to the standard. The overall incubation time was 3 hours in total, with 30 minutes of hands-on time. Each sample was run in duplicates.

\section{Clinical data and statistical analysis}

The clinical data for each subject were obtained from the patient's medical records. The statistical analyses were performed using SPSS 25.0 software (RRID:SCR_002865). Normality test was performed using the Shapiro-Wilk test. Continuous data were analysed using independent T-test with equal variances assumed. Furthermore, categorical data were analysed using Fisher's Exact Test. The correlation between UCB volume and UCB parameters was calculated using Spearman's rank-order test. Data were shown in mean \pm SD, and significance is denoted with a $p$-value of less than 0.05 .

\section{Results}




\section{Clinical Data Analysis}

Overall, the mean age of women with GDM in this study was 30.81 years (ranged between 28-34 years old [Table 1]). The body mass index (BMI) was significantly higher in women with GDM compared to the control group $(p<0.0005)$. The average gestational age at delivery was 37.89 in the GDM group, which was significantly lower compared to the control group $(p=0.031$; Table 1$)$. Meanwhile, the rate of caesarean section in the GDM group was relatively high compared to the control group $(p=0.028$; Table 1).

TABLE 1 A comparison of maternal \& foetal characteristics in GDM and Control groups.

\begin{tabular}{|c|c|c|c|}
\hline Parameter & $\begin{array}{l}\text { GDM } \\
(\mathrm{n}=42)\end{array}$ & $\begin{array}{c}\text { Control } \\
(n=38)\end{array}$ & $P$ Value \\
\hline Mother's age & $30.81 \pm 0.58$ & $29.89 \pm 0.54$ & $0.534 ¥$ \\
\hline Body mass index (BMI) & $26.7 \pm 0.4$ & $22.8 \pm 0.5$ & $<0.0005 ¥$ \\
\hline Pregnancy duration (week) & $37.89 \pm 0.22$ & $38.55 \pm 0.19$ & $0.031 ¥$ \\
\hline Leucocyte count (x109/L) & $11.04 \pm 0.53$ & $11.06 \pm 0.43$ & $0.978 ¥$ \\
\hline $\begin{array}{c}\text { *Gravidity } \\
1-3 \\
4-6\end{array}$ & $\begin{array}{c}35(83.33 \%) \\
7(16.66 \%)\end{array}$ & $\begin{aligned} 36 & (94.74 \%) \\
2 & (5.26 \%)\end{aligned}$ & $0.159 \square$ \\
\hline Systolic pressure (mmHg) & $120.74 \pm 1.57$ & $120.21 \pm 1.81$ & $0.825 ¥$ \\
\hline Diastolic pressure (mmHg) & $70.49 \pm 1.49$ & $69.38 \pm 1.47$ & $0.459 ¥$ \\
\hline $\begin{array}{l}\text { *Delivery method } \\
\text { SVD } \\
\text { LUSCS }\end{array}$ & $\begin{array}{l}32(47.05 \%) \\
10(83.33 \%)\end{array}$ & $\begin{array}{c}36(52.95 \%) \\
2(16.67 \%)\end{array}$ & 0.028 \\
\hline $\begin{array}{l}\text { Baby weight }(\mathrm{kg}) \\
\text { Placenta weight }(\mathrm{g})\end{array}$ & $\begin{array}{c}3.03 \pm 0.07 \\
582.70 \pm 16.81\end{array}$ & $\begin{array}{c}3.08 \pm 0.06 \\
600.00 \pm 15.71\end{array}$ & $\begin{array}{l}0.916 ¥ \\
0.747 ¥\end{array}$ \\
\hline
\end{tabular}

Notes: $¥$ Independent sample $\mathrm{T}$ test (Data shown in mean \pm SD)

$\square$ Fisher's Exact test

$p$ value is significant $<0.05$

*Shown as frequency

Abbrev: SVD=Spontaneous Vaginal Delivery, LUSCS=Lower Uterine Segment Caesarean Section 
The correlation between UCB volume and parameters such as nucleated cell count (NCC), total nucleated cell (TNC), CD34+ cell count, and total CD34+ cell was further analysed (Table 2). Our data showed that all UCB parameters were significantly decreased in the GDM group compared to the control group $(p<0.0005$; Table 2$)$. The TNC and CD34+ cell counts in the GDM group were half lower than the control group (Table 2).

TABLE 2 A comparisons of UCB Parameters in GDM and Control groups.

\begin{tabular}{|c|c|c|c|}
\hline Parameter & $\begin{array}{l}\text { GDM } \\
(\mathrm{n}=42)\end{array}$ & $\begin{array}{l}\text { Control } \\
(n=38)\end{array}$ & $P$ Value \\
\hline \multirow[t]{2}{*}{ Volume (mL) } & $80.36 \pm 1.88$ & $102.16 \pm 2.43$ & \\
\hline & & & $<0.0005$ \\
\hline \multirow[t]{2}{*}{ NCC $\left(x 10^{6} \mathrm{cell} / \mathrm{mL}\right)$} & $4.74 \pm 0.30$ & $9.03 \pm 0.46$ & \\
\hline & & & $<0.0005$ \\
\hline \multirow[t]{2}{*}{ TNC ( $x 10^{8}$ cell $)$} & $3.87 \pm 0.29$ & $9.36 \pm 0.62$ & \\
\hline & & & $<0.0005$ \\
\hline \multirow[t]{2}{*}{$\mathrm{CD} 34^{+}$count $(\mathrm{cell} / \mu \mathrm{L})$} & $61.18 \pm 6.64$ & $125.60 \pm 9.75$ & \\
\hline & & & $<0.0005$ \\
\hline Total CD34 ${ }^{+}$ & $4.88 \pm 0.55$ & $13.07 \pm 1.11$ & \\
\hline Count (x10 6 cell) & & & $<0.0005$ \\
\hline
\end{tabular}

Notes: $¥$ Independent sample $\mathrm{T}$ test (Data shown in mean \pm SD) $p$ value is significant $<0.05$

Abbrev: NCC=nucleated cell count; $T N C=$ total nucleated count.

\section{EPO analysis}

The average EPO concentration for the GDM and control groups were $1562.9 \mathrm{pg} / \mathrm{mL}$ and $601.8 \mathrm{pg} / \mathrm{mL}$ (Figure 1). The EPO level was significantly higher in the GDM group compared to the control group $(p<0.0005$; Figure 1). Overall, no correlation was observed between UCB parameters and the EPO level in both GDM and the control group, except for the reduced TNC counts, which was significantly correlated with a higher EPO level in the GDM group $(p=0.033$; Table 3$)$.

TABLE 3

A correlation between UCB parameters and EPO level in GDM and Control groups. 


\begin{tabular}{|c|c|c|c|c|c|c|c|}
\hline Group & EPO & $\begin{array}{c}\text { Volume } \\
\text { (ml) }\end{array}$ & $\begin{array}{l}\text { NCC } \\
\left(\mathrm{x} 10^{6}\right)\end{array}$ & TNC & $\left(\mathrm{x} 10^{8}\right)$ & $\mathrm{CD} 4^{+}(\mathrm{cell} / \mu \mathrm{L})$ & $\begin{array}{c}\text { Total CD34 } \\
\left(\mathrm{x} 10^{6}\right)\end{array}$ \\
\hline $\begin{array}{l}\text { Control } \\
(n=38)\end{array}$ & $\begin{array}{l}\text { Nilai } p \\
\text { Nilai } r\end{array}$ & $\begin{array}{c}0.859 \\
-0.030\end{array}$ & $\begin{array}{c}0.896 \\
-0.022\end{array}$ & & $\begin{array}{l}0.956 \\
0.009\end{array}$ & $\begin{array}{c}0.215 \\
-0.206\end{array}$ & $\begin{array}{c}0.202 \\
-0.212\end{array}$ \\
\hline $\begin{array}{l}\text { GDM } \\
(n=42)\end{array}$ & $\begin{array}{l}\text { Nilai } p \\
\text { Nilai } r\end{array}$ & $\begin{array}{l}0.087 \\
0.268\end{array}$ & $\begin{array}{l}0.243 \\
0.184\end{array}$ & & $\begin{array}{l}\mathbf{0 . 0 3 3} \\
0.329\end{array}$ & $\begin{array}{l}0.072 \\
0.281\end{array}$ & $\begin{array}{l}0.612 \\
0.080\end{array}$ \\
\hline
\end{tabular}

Notes: $p$ values based on statistic Spearman's rank order statistical analysis. $p$ value is significant $<0.05$

Abbrev: NCC=nucleated cell count; TNC=total nucleated count.

\section{Insulin analysis}

The average insulin concentrations for the GDM and control groups were $62.28 \mathrm{pmol} / \mathrm{L}$ and $54.2 \mathrm{pmol} / \mathrm{L}$ (Figure 2). No significant difference was noted between the two groups studied. Overall, no significant correlation was observed between UCB parameters and insulin level in the GDM and control groups (Table 4).

TABLE 4 A correlation between UCB parameters and insulin level in GDM and Control groups.

\begin{tabular}{|c|c|c|c|c|c|c|c|}
\hline Group & Insulin & $\begin{array}{l}\text { Volume } \\
(\mathrm{ml})\end{array}$ & $\begin{array}{l}\text { NCC } \\
\left(x 10^{6}\right)\end{array}$ & TNC & $\left(\mathrm{x} 10^{8}\right)$ & $\mathrm{CD}^{+} 4^{+}(\mathrm{cell} / \mu \mathrm{L})$ & $\begin{array}{c}\text { Total CD34 } \\
\left(\mathrm{x} 10^{6}\right)\end{array}$ \\
\hline $\begin{array}{l}\text { Control } \\
(n=38)\end{array}$ & $\begin{array}{l}\text { Nilai } p \\
\text { Nilai } r\end{array}$ & $\begin{array}{c}0.558 \\
-0.098\end{array}$ & $\begin{array}{l}0.465 \\
0.122\end{array}$ & & $\begin{array}{l}0.674 \\
0.071\end{array}$ & $\begin{array}{l}0.959 \\
0.009\end{array}$ & $\begin{array}{c}0.646 \\
-0.077\end{array}$ \\
\hline $\begin{array}{l}\text { GDM } \\
(n=42)\end{array}$ & $\begin{array}{l}\text { Nilai } p \\
\text { Nilai } r\end{array}$ & $\begin{array}{r}0.730 \\
-0.055\end{array}$ & $\begin{array}{l}0.456 \\
0.118\end{array}$ & & $\begin{array}{l}0.658 \\
0.070\end{array}$ & $\begin{array}{c}0.411 \\
-0.130\end{array}$ & $\begin{array}{c}0.908 \\
-0.018\end{array}$ \\
\hline
\end{tabular}

Notes: $p$ values based on statistic Spearman's rank order statistical analysis. $p$ value is significant $<0.05$

Abbrev: NCC=nucleated cell count; TNC=total nucleated count.

\section{The haematopoietic differentiation of CD34+ enriched cell by CFU assay}

We observed the CFU of all types of progenitors at 14 days post-incubation. The CFU-GEMM $(p<0.0005)$, CFU-GM $(p<0.0005)$, CFU-G $(p=0.001)$, and CFU-M $(p<0.0005)$ colonies were significantly reduced in the GDM group compared to the control group (Table 5). Interestingly, this study showed a high number of BFU-E colonies forming in the GDM group $(94.19 \pm 6.21)$ compared to the control group $(73.61 \pm 2.73$; $p=0.01 ;$ Table 5).

TABLE 5 A comparison of progenitors counts in GDM and Control groups. 


\begin{tabular}{cccc}
\hline Types of progenitor & $\begin{array}{c}\text { GDM } \\
(\mathbf{n}=\mathbf{4 2})\end{array}$ & $\begin{array}{c}\text { Control } \\
(\mathrm{n}=\mathbf{3 8})\end{array}$ & $P$ value \\
\hline CFU-GEMM & $65.98 \pm 2.98$ & $87.45 \pm 1.46$ & $<0.0005$ \\
CFU-GM & $49.50 \pm 3.06$ & $70.92 \pm 1.93$ & $<0.0005$ \\
& & & \\
BFU-E & $94.19 \pm 6.21$ & $73.61 \pm 2.73$ & 0.010 \\
& & & \\
CFU-G & $70.55 \pm 4.00$ & $89.21 \pm 1.46$ & $\mathbf{0 . 0 0 1}$ \\
& & & \\
CFU-M & $62.79 \pm 3.93$ & $81.39 \pm 1.76$ & $<0.0005$ \\
& & & \\
\hline
\end{tabular}

Notes: $¥$ Independent sample $\mathrm{T}$ test (Data shown in mean \pm SD)

$p$ value is significant $<0.05$

Abbrev: CFU-GEMM=Colony Forming Unit granulocyte erythrocyte monocyte megakaryocyte, CFU-GM=Colony Forming Unit granulocyte monocyte, BFU-E=Burst Forming Unit Erythroid $C F U-G=$ Colony Forming Unit granulocyte and CFU-M=Colony Forming Unit megakaryocyte

\section{Discussion}

\section{Statement of principle findings}

This study has demonstrated that GDM in pregnancy affected the UCB volume, TNC, and total CD34+ cell counts. Furthermore, the CFU assay has confirmed the adverse effect of GDM in terms of the ability of UCB-HSC to differentiate into progenitor colonies. The GDM group exhibited a significantly reduced number of CFU colonies, except for the high BFU-E, suggesting an active erythropoiesis process due to abnormal placental blood flow and hypoxia. These data also demonstrated a high EPO level in the GDM group. Although the EPO level was significantly higher in GDM, the insulin level was comparable to that of the control group.

\section{Findings in context of existing research}

\section{Gestational age is shorter in the group of GDM than in the control group}

Gestational age factor showed a significant difference between the group of GDM mothers compared to the control group ( $p=0.031$ ), with an average week at 37.89 for the GDM group. This early birth could be due to the risk of the disease itself or iatrogenic syndrome, which requires the patient to give birth earlier 
(19). These data are in line with the relatively high percentage of caesarean delivery methods (83.33\%) in the GDM group.

\section{UCB volume decreased in GDM pregnancy probably due to placental microvascular pathology}

The UCB volume in the GDM group was significantly lower than the control group ( $p<0.0005$; Table 2). The difference was as expected based on the pathophysiology of DM. It has been reported that the production of prostacyclin, a blood vessel development agent, is reduced in DM patients, causing vasoconstriction of utero-placental blood vessels (20). This will lead to the presence of a smaller UCB volume. For UCB banking, the volume of UCB is a critical criterion for further processing and retrieval, as this will determine the number of $\mathrm{CD} 34+$ cell required for downstream treatment.

\section{NCC and TNC counts were reduced in GDM pregnancy and did not meet the international cell transplant standards for processing and cryopreservation}

The NCC and TNC values in the GDM group were half of the control group. According to the standards of UCB banks, the minimum value of TNC for processing and cryopreservation is $4-6^{\prime} 10^{8}$ cells $(21,22)$. However, the average value of TNC in the GDM group is $3.87^{\prime} 10^{8}$ cells (Table 2), which may be considered for processing and cryopreservation. TNC count is an important parameter for the prediction of the survival and mortality outcomes following HSC transplantation. The TNC transplant required a standard TNC count of $1-3^{\prime} 10^{7}$ cells $/ \mathrm{kg}$ weight of the receiver. A higher TNC count will give better transplant outcomes, including reduced mortality (21).

\section{Total CD34+ cell count reduced in GDM group and only sufficient for child recipients}

The GDM group had significantly lower total CD34+ cell counts compared to the control group. The number of CD34+ cells is an important parameter for assessing the efficacy of transplantation in terms of post-transplant survival and mortality. A study conducted in patients who received a higher CD34+ cell count $\left(>1.7^{\prime} 10^{5} \mathrm{CD} 34+/ \mathrm{kg}\right)$ showed a reduced mortality rate (4). Our data showed a mean total of $4.88^{\prime}$ $10^{6} \mathrm{CD} 34+$ cells in the GDM group (Table 2), suggesting that children aged between 5-11 years (with less than $28 \mathrm{~kg}$ weight) would be suitable recipients.

\section{The insulin concentration of UCB in the GDM group is comparable to the control group and does not affect HSC quality}

Early and intensive treatment provided by the clinical team at UKMMC to pregnant mothers with GDM likely contribute to a controlled insulin level. This was done through dietary plans and insulin control. The UCB insulin assessment of the GDM group is very useful in monitoring the level of foetal exposure to glucose in utero. Foetus exposed to hyperinsulinemia has the potential to develop illnesses such as diabetes, abnormal glucose tolerance, and metabolic complications later in life (23). However, the association between the level of insulin and HSC quality is not well studied. It was also reported that angiogenesis and vascularisation changes might affect the quality of HSC (11). 


\section{GDM group showed reduced number of differentiated haematopoietic progenitor colonies as compared to control group}

These outcomes are consistent with previous studies that identified pregnant mothers with PE (24). However, no such research on GDM patients has yet been published. The generation of HSC in the placenta and umbilical cord during pregnancy is quite complex and not well understood. Gekas et al. indicated that the placental microenvironment is rich in cytokines and growth factors, properties that support the expansion of HSC (25). Theoretically, GDM could alter the properties of the placental microenvironment (25), suggesting reduced progenitors count in the GDM group. In addition, the higher number of progenitor cells in the control group could be due to the decent quality of CD34+ cells. The CD34+ cell is a haematopoietic cell that undergoes haematopoiesis in the clonogenic assay (26). The high number of colonies in the control group indicates that these unobstructed CD34+ cells could differentiate and sprout.

\section{The number of BFU-E colonies is higher in the GDM group compared to the control group}

BFU-E is a progenitor cell colony produced by more than 200 erythroblasts that undergo erythropoiesis. This finding is similar to the previous study on UCB of premature infants (27). However, the study of Wisgrill et al. (2014) showed a high number of CD34+ cells in premature UCB and suggested that stress in these premature infants caused instability of cytokine and chemokine levels. This phenomenon affected the haematopoiesis process (27). However, in this study, the CD34+ cell count in the GDM group was lower than the control group, suggesting that the high number of colonies of BFU-E is likely due to an active erythropoiesis process. Erythropoiesis is the process mediated by EPO, which produces red blood cells. In addition, high oxygen demand in foetal hyperinsulinemia syndrome also affects the process of aerobic metabolism that causes changes in the erythropoiesis process. In this study, the EPO assay was performed to further investigate the correlation between EPO level and HSC quality, predominantly with the high number of BFU-E colonies in the GDM group.

\section{The high number of BFU-E colonies is probably due to an increased level of EPO in the GDM group}

Generally, the quality of HSC is translated as the capacity of HSC to differentiate and form various haematopoietic colonies observed through the CFU assay. A high EPO level in the GDM group may also explain the high number of BFU-E colonies. Previous studies have shown that most cases of GDM have increased foetal oxidative stress, which is thought to play a role in maternal and foetal complications of diabetic pregnancies (28). Oxidative stress is also related to the degree of increased development of EPO; hence, polycythaemia in the infant. This leads to a rise in UCB EPO levels following the activation of erythropoietic processes (29) and the incidence of polycythaemia in the newborn (30). The increased number of BFU-E colony in the GDM group corresponds to an increased EPO level, probably due to hypoxia affecting the placenta.

\section{Limitations and recommendation of the study}


Among the limitation of the study is the limited sample size. A larger sample in the future may help confirm our findings concerning EPO and CFU assays. Another limitation is that the study was conducted in a single hospital, potentially contributing to inadequate representation of the general population. We recommend that this study be expanded to other hospitals in the future.

\section{Conclusion}

Preliminary findings from this study indicate that GDM influenced the quality of UCB-HSC. These results would be useful for physicians and mothers concerning the decision on UCB banking. In addition, studies on cytokines such as osteopontin and other growth factors should also be considered to better comprehend their effect on the quality of UCB-HSC and their association with placental development.

\section{Implication of the findings}

To date, no studies have reported the correlation of EPO and insulin level with the quality of UCB-HSC. Thus, this study serves as a foundation to further investigate the effect of these cytokines on the quality of HSC, especially in UCB, as it is suggested that these abnormalities might interfere with the quality of HSC production.

\section{Abbreviations}

UCB-Umbilical cord blood

HSC-Hematopoietic Stem Cell

GDM-Gestational Diabetes Mellitus

TNC-Total Nucleated Cell

CFU-Colony Forming Unit

NCC-Nucleated Cell Count

CFU-GM-Colony forming unit granulocyte monocyte

CFU-G-Colony forming unit granulocyte

CFU-GEMM-Colony forming unit granulocyte, erythrocyte, monocyte, megakaryocyte

CFU-M-Colony forming unit megakaryocyte

BFU-E-Burst forming unit erythroid

MNC-Mononuclear cell 
LUSCS-Lower uterine segment caesarean segment

SVD-Spontaneous vaginal delivery

BMI-Body mass index

\section{Declarations}

\section{Ethics approval and consent to participate}

This study was reviewed and approved by the Research Ethics Committee of UKM (UKM

1.5.3.5/244/FRGS/2/2013/SKK01/UKM/03/2). All participants provided written informed consent to participate.

\section{Consent for publication}

All participants provided written informed consent for publication.

\section{Availability of data and materials}

The datasets used and analysed during the current study are available from the corresponding author on reasonable request.

\section{Competing interests}

The authors declare that they have no competing interests.

\section{Funding}

The study was supported by the Ministry of Higher Education Malaysia (MOHE) through a grant FRGS/2/2013/SKK01/UKM/03/2. This funding body accepted the study as proposed.

\section{Authors Contributions'}

MRI conducted the study; FN, ZAM and SFAW contributed to the design of the study; MRI and FN wrote this manuscript and involved in the collection of the data and analysis. All authors have read and approved the final version of the manuscript.

\section{ACKNOWLEDGEMENT}

We would like to thank members of the Department of Obstetrics and Gynaecology, UKM Medical Centre, for their support and assistance, especially with the sample collection.

\section{References}


1. Gluckman E. Current status of umbilical cord blood hematopoietic stem cell transplantation. Experimental hematology. 2000;28(11):1197-205.

2. Rocha V, Wagner Jr JE, Sobocinski KA, Klein JP, Zhang M-J, Horowitz MM, et al. Graft-versus-host disease in children who have received a cord-blood or bone marrow transplant from an HLA-identical sibling. New England Journal of Medicine. 2000;342(25):1846-54.

3. Chao NJ, Emerson SG, Weinberg KI. Stem cell transplantation (cord blood transplants). ASH Education Program Book. 2004;2004(1):354-71.

4. Wagner JE, Barker JN, DeFor TE, Baker KS, Blazar BR, Eide C, et al. Transplantation of unrelated donor umbilical cord blood in 102 patients with malignant and nonmalignant diseases: influence of CD34 cell dose and HLA disparity on treatment-related mortality and survival. Blood. 2002;100(5):1611-8.

5. Scaradavou A, Brunstein CG, Eapen M, Le-Rademacher J, Barker JN, Chao N, et al. Double unit grafts successfully extend the application of umbilical cord blood transplantation in adults with acute leukemia. Blood. 2013;121(5):752-8.

6. Rocha V, Labopin M, Sanz G, Arcese W, Schwerdtfeger R, Bosi A, et al. Acute Leukemia Working Party of European Blood and Marrow Transplant Group; Eurocord-Netcord Registry. Transplants of umbilical-cord blood or bone marrow from unrelated donors in adults with acute leukemia. $\mathrm{N}$ Engl J Med. 2004;351(22):2276-85.

7. George TJ, Sugrue MW, George SN, Wingard JR. Factors associated with parameters of engraftment potential of umbilical cord blood. Transfusion. 2006;46(10):1803-12.

8. Kampan N, Azman H, Hafiz I, Mohammad H, Yee CS, Abdul Ghani N. Outcome of pregnancy among Malaysian women with diabetes mellitus-a single centre experience. Malaysian Journal of Public Health Medicine. 2013;13(2):1-10.

9. Shamsuddin K, Mahdy Z, Siti Rafiaah I, Jamil M, Rahimah M. Risk factor screening for abnormal glucose tolerance in pregnancy. International Journal of Gynecology \& Obstetrics. 2001;75(1):27-32.

10. Kaaja R, Rönnemaa T. Gestational diabetes: pathogenesis and consequences to mother and offspring. The review of diabetic studies: RDS. 2008;5(4):194.

11. Gauster M, Desoye G, Totsch M, Hiden U. The placenta and gestational diabetes mellitus. Curr Diab Rep. 2012;12(1):16-23.

12. Teramo KA. Obstetric problems in diabetic pregnancy-the role of fetal hypoxia. Best Practice \& Research Clinical Endocrinology \& Metabolism. 2010;24(4):663-71.

13. Cetin $H$, Yalaz M, Akisu M, Kultursay N. Polycythaemia in infants of diabetic mothers: $\beta$ hydroxybutyrate stimulates erythropoietic activity. Journal of International Medical Research. 2011;39(3):815-21.

14. Shannon K, Davis JC, Kitzmiller JL, Fulcher SA, Koenig HM. Erythropoiesis in infants of diabetic mothers. Pediatric research. 1986;20(2):161.

15. Teramo KA, Widness JA. Increased Fetal Plasma and Amniotic Fluid Erythropoietin Concentrations: Markers of Intrauterine Hypoxia. Neonatology. 2009;95(2):105-16. 
16. Di Cianni G, Miccoli R, Volpe L, Lencioni C, Del Prato S. Intermediate metabolism in normal pregnancy and in gestational diabetes. Diabetes/metabolism research and reviews. 2003;19(4):25970.

17. Santillan DA, Hamilton WS, Christensen A, Talcott KM, Gravatt LK, Santillan MK, et al. The effects of preeclampsia on signaling to hematopoietic progenitor cells. 2013.

18. Randel A. ACOG Releases Guideline on Gestational Diabetes. American family physician. 2014;90(6):416-7.

19. Persson M, Pasupathy D, Hanson U, Westgren M, Norman M. Pre-pregnancy body mass index and the risk of adverse outcome in type 1 diabetic pregnancies: a population-based cohort study. BMJ open. 2012;2(1):e000601.

20. Hadi HA, Al Suwaidi J. Endothelial dysfunction in diabetes mellitus. Vascular health and risk management. 2007;3(6):853.

21. Nakagawa R, Watanabe T, Kawano Y, Kanai S, Suzuya H, Kaneko M, et al. Analysis of maternal and neonatal factors that influence the nucleated and CD34+ cell yield for cord blood banking. Transfusion. 2004;44(2):262-7.

22. Jaime-Perez JC, Monreal-Robles R, Rodriguez-Romo LN, Mancias-Guerra C, Herrera-Garza JL, GomezAlmaguer D. Evaluation of volume and total nucleated cell count as cord blood selection parameters: a receiver operating characteristic curve modeling approach. American journal of clinical pathology. 2011;136(5):721-6.

23. Westgate JA, Lindsay RS, Beattie J, Pattison NS, Gamble G, Mildenhall LF, et al. Hyperinsulinemia in cord blood in mothers with type 2 diabetes and gestational diabetes mellitus in New Zealand. Diabetes care. 2006;29(6):1345-50.

24. Surbek DV, Danzer E, Steinmann C, Tichelli A, Wodnar-Filipowicz A, Hahn S, et al. Effect of preeclampsia on umbilical cord blood hematopoietic progenitor-stem cells. American journal of obstetrics and gynecology. 2001;185(3):725-9.

25. Gekas C, Rhodes KE, Van Handel B, Chhabra A, Ueno M, Mikkola HK. Hematopoietic stem cell development in the placenta. The International journal of developmental biology. 2010;54:1089.

26. Sarı T, Yüksel MK, Topçuoğlu P, Tol M, Ayyıldız E, Özcan M, et al. The effect of CD34 count and clonogenic potential of hematopoietic stem cells on engraftment. Transfusion and Apheresis Science. 2010;43(3):315-20.

27. Wisgrill L, Schüller S, Bammer M, Berger A, Pollak A, Radke TF, et al. Hematopoietic stem cells in neonates: any differences between very preterm and term neonates? PloS one. 2014;9(9):e106717.

28. Fadda GM, D'Antona D, Ambrosini G, Cherchi PL, Nardelli GB, Capobianco G, et al. Placental and fetal pulsatility indices in gestational diabetes mellitus. The Journal of reproductive medicine. 2001;46(4):365-70.

29. Madazlı R, Tuten A, Calay Z, Uzun H, Uludag S, Ocak V. The incidence of placental abnormalities, maternal and cord plasma malondialdehyde and vascular endothelial growth factor levels in women 
with gestational diabetes mellitus and nondiabetic controls. Gynecologic and obstetric investigation. 2008;65(4):227-32.

30. Hadarits O, Zóka A, Barna G, Al-Aissa Z, Rosta K, Rigó Jr J, et al. Increased proportion of hematopoietic stem and progenitor cell population in cord blood of neonates born to mothers with gestational diabetes mellitus. Stem cells and development. 2015;25(1):13-7.

\section{Figures}

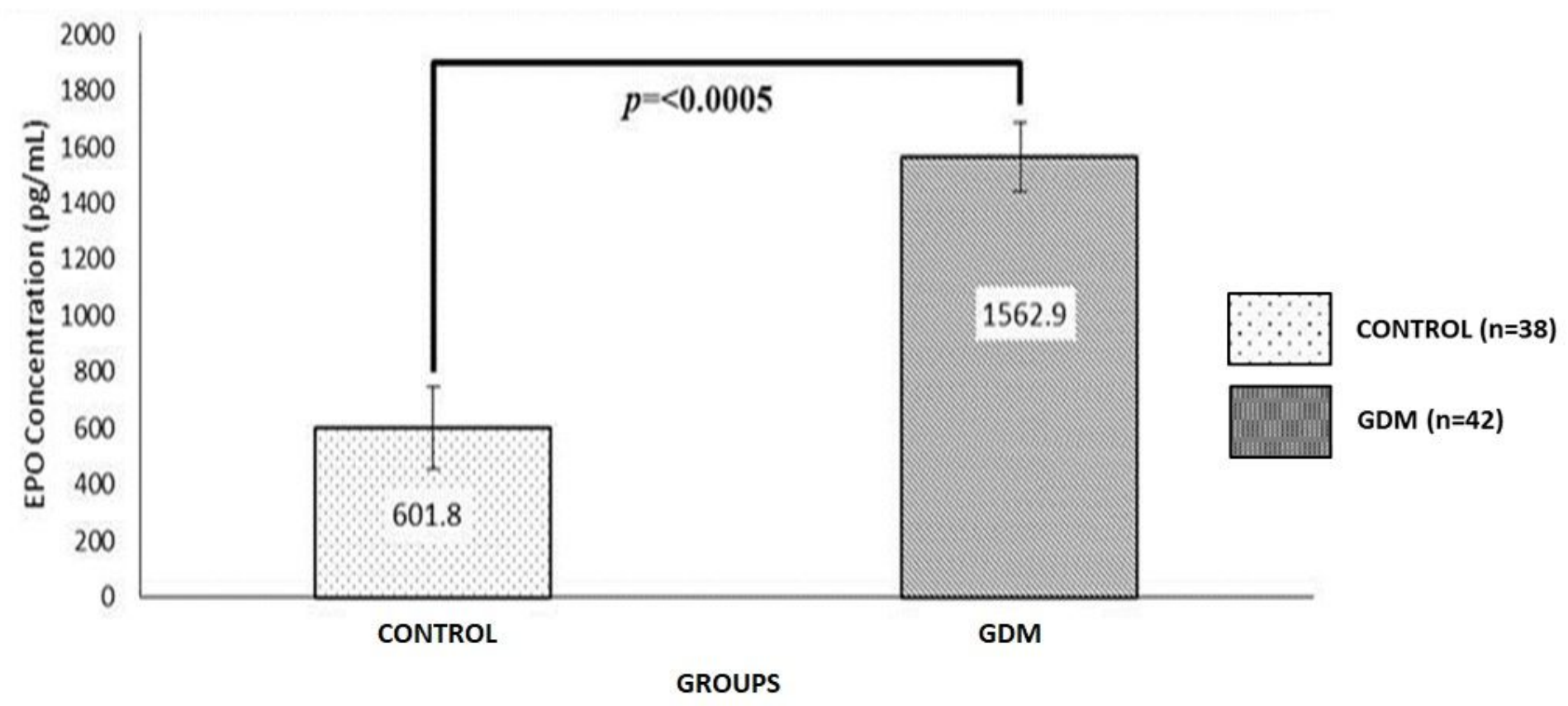

Figure 1

Comparison of EPO UCB concentration ( $\mathrm{pgmol} / \mathrm{mL}$ ) between GDM and Control groups. The EPO level was significantly higher in GDM as compared to the Control group $(p=<0.0005)$. 


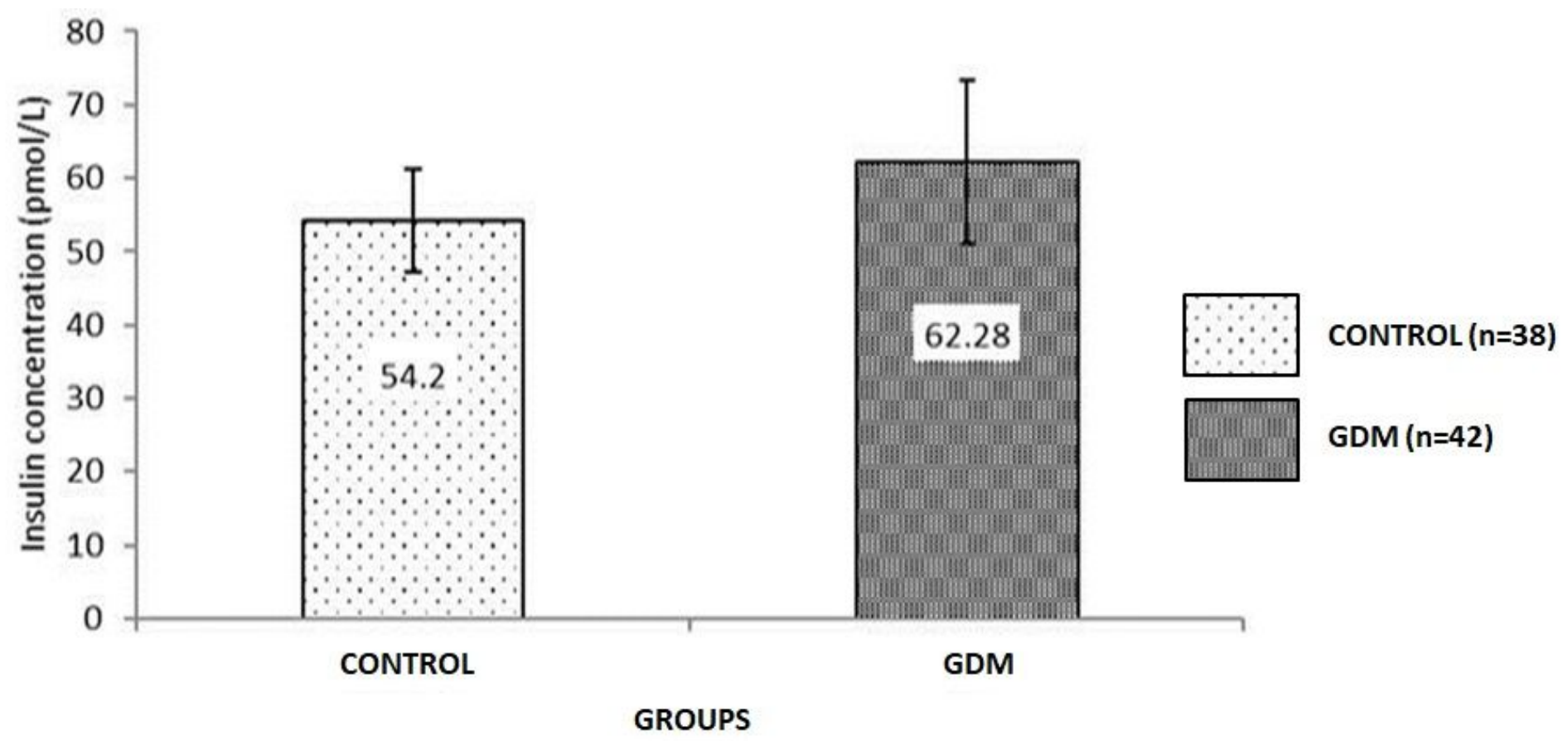

Figure 2

Comparison of insulin UCB (pmol/L) concentration between GDM and Control groups. The insulin level in the GDM group is comparable with the Control group. Data shown is mean $\pm S E M$.

\section{Supplementary Files}

This is a list of supplementary files associated with this preprint. Click to download.

- ADDITIONALFILE1.GDM.pptx

- ADDITIONALFILE2.GDM.pptx 